\title{
BMJ Open Quality Lessons learned: using adverse incident reports to investigate the characteristics and causes of prescribing errors
}

\author{
Natalie Lane (D) ,1,2 Ian Hunter ${ }^{1}$
}

To cite: Lane N, Hunter I. Lessons learned: using adverse incident reports to investigate the characteristics and causes of prescribing errors. BMJ Open Quality 2020;9:e000949. doi:10.1136/ bmjoq-2020-000949

Received 16 February 2020 Revised 12 May 2020 Accepted 4 June 2020
Check for updates

(C) Author(s) (or their employer(s)) 2020. Re-use permitted under CC BY-NC. No commercial re-use. See rights and permissions. Published by BMJ.

${ }^{1}$ Department of Medical Education, NHS Lanarkshire, Bothwell, Scotland, UK

${ }^{2}$ Department of Psychiatry, NHS Lanarkshire, Bothwell, Scotland, UK

Correspondence to Dr Natalie Lane; natalie.lane@nhs.net

\begin{abstract}
Introduction Prescribing errors are a principal cause of preventable harm in healthcare. This study aims to establish a systematic approach to analysing prescribingrelated adverse incident reports, in order to elucidate the characteristics and contributing factors of common prescribing errors and target multifaceted quality improvement initiatives.
\end{abstract}

Methods All prescribing-related adverse incident reports submitted across one NHS board over 12 months were selected. Incidents involving commonly implicated drugs (involved in $\geq 10$ incidents) underwent analysis to establish likely underlying causes using Reason's Model of Accident Causation.

Results 330 prescribing-related adverse incident reports were identified. Commonly implicated drugs were insulin (10\% of incidents), gentamicin (7\%), co-amoxiclav (5\%) and amoxicillin $(5 \%)$. The most prevalent error types were prescribing amoxicillin when contraindicated due to allergy (5\%); prescribing co-amoxiclav when contraindicated due to allergy (5\%); prescribing the incorrect type of insulin (3\%); and omitting to prescribe insulin (3\%). Error-producing factors were identified in $86 \%$ of incidents involving commonly implicated drugs. $53 \%$ of incidents involved error-producing factors related to the working environment; $38 \%$ involved factors related to the healthcare team; and $37 \%$ involved factors related to the prescriber.

Discussion This study establishes that systematic analysis of adverse incident reports can efficiently identify the characteristics and contributing factors of common prescribing errors, in a manner useful for targeting quality improvement. Furthermore, this study produced a number of salient findings. First, a narrow range of drugs were implicated in the majority of incidents. Second, a small number of error types were highly recurrent. Lastly, a range of contributing factors were evident, with those related to the working environment contributing to the majority of prescribing errors analysed.

\section{INTRODUCTION}

Prescribing errors are a principal cause of preventable harm in healthcare. ${ }^{1}$ Recent guidelines advocate utilising readily accessible information present within prescribingrelated adverse incident reports to identify factors contributing to errors. ${ }^{2} 3$ This study aims to establish a systematic approach to analysing prescribing-related adverse incident reports within one NHS board, in order to elucidate the characteristics and contributing factors of common prescribing errors, and subsequently target multifaceted quality improvement initiatives.

\section{METHODS}

According to local policy, this work met criteria for improvement activities exempt from ethics review.

All adverse incident reports submitted via the Datix system in one NHS board over 12 months (February 2017 to February 2018) were identified. Those categorised as 'medication prescribing incidents' by the reporter were selected. Furthermore, all incidents reported by doctors were screened, and those regarding prescribing were also selected. The drug(s) involved in each prescribing-related incident were identified. A list of commonly implicated drugs (involved in $\geq 10$ incidents) was collated.

Incidents involving commonly implicated drugs underwent analysis to establish contributing factors. The reporter's free-text description of the incident was evaluated using Reason's Model of Accident Causation. This framework categorises conditions that increase the probability of an error occurring into those inherent to the prescriber (eg, lack of knowledge); the working environment (eg, heavy workload); the healthcare team (eg, poor handover); the prescribing task (eg, difficulty accessing electronic records); and the patient (eg, complex comorbidities). ${ }^{45}$

\section{RESULTS}

In total, 330 prescribing-related incident reports were identified. Of these, $41 \%$ were submitted by pharmacists; $24 \%$ by nurses; and $10 \%$ by doctors. Of note, $84 \%$ resulted in no obvious harm; $9 \%$ caused minor, nonpermanent harm; and 7\% caused moderate, semipermanent harm. 
A total of 167 named drugs were involved in the 330 incidents. Commonly implicated drugs were insulin $(10 \%$ of incidents), gentamicin (7\%), co-amoxiclav (5\%), amoxicillin $(5 \%)$, enoxaparin $(4 \%)$, warfarin $(4 \%)$, aspirin $(3 \%)$, paracetamol $(3 \%)$, vancomycin $(3 \%)$, morphine (3\%) and tinzaparin (3\%). Errors involving these 11 drugs accounted for $51 \%$ of incident reports.

The most common error types were prescribing amoxicillin when contraindicated due to allergy $(4.8 \%$ of incidents); prescribing co-amoxiclav when contraindicated due to allergy $(4.5 \%)$; prescribing the incorrect insulin type $(3.3 \%)$; inappropriately omitting to prescribe insulin $(3.0 \%)$; prescribing the incorrect gentamicin dose $(2.1 \%)$; incorrect gentamicin level monitoring $(2.1 \%)$; and prescribing gentamicin in the incorrect dosage frequency $(1.8 \%$, table 1$)$.

Error-producing conditions were identified in $86 \%$ of incidents involving commonly implicated drugs. In $53 \%$ of incidents, error-producing factors related to the working environment were evident. The most prevalent environmental factors were workload and time pressure in medical receiving $(27 \%)$; workload and time pressure in accident and emergency (5\%); prescribing for unfamiliar patients (4\%, eg, ward junior doctors prescribing insulin for patients boarding from other specialties); and workload and time pressure while on-call $(4 \%)$.

In addition, error-producing factors related to the healthcare team were found in $38 \%$ of incidents. The most commonly implicated team factors were different teams looking after one patient (eg, duplication of antibiotic prescription by Accident \& Emergency and Medical teams, $16 \%$ ); poor communication between medical and nursing staff $(11 \%)$; and poor communication between medical staff $(10 \%)$.

Furthermore, error-producing factors related to the individual prescriber were identifiable in $37 \%$ of incidents. The most prevalent prescriber factors were lack of knowledge of insulin types (6\%); lack of knowledge of gentamicin level monitoring (4\%); lack of knowledge regarding coprescribing of anticoagulants $(2 \%)$; and lack of knowledge regarding omitting insulin (2\%).

Lastly, error-producing factors related to the patient and the prescribing task were less commonly identified (13\% and $11 \%$ of incidents, respectively). Patient factors included inaccurate knowledge of their own medications (contributing to errors in medicines reconciliation, 6\%); and complexity due to anticoagulation (invalidating generic thromboprophylaxis guidelines, 3\%). The most common task factor was unavailability of medication information on admission (eg, inability to access electronic patient records, $4 \%$ ).

\section{DISCUSSION}

This study illustrates that analysis of prescribing-related incident reports provides a simple and efficient method of identifying the characteristics and contributing factors of common prescribing errors.
Furthermore, a number of salient findings were produced. First, a narrow range of 11 drugs were involved in over $50 \%$ of incidents. Second, a small number of error types were highly recurrent, namely: prescribing of penicillins in allergy; omission of insulin; and prescription of the incorrect insulin type.

In addition, analysis using Reason's framework revealed a range of contributing factors. Most significantly, factors related to the working environment were deemed contributory to $53 \%$ of analysed incidents. Factors related to the healthcare team, and those related to the prescriber, were considered relevant to a significant minority of incidents (38\% and 37\%, respectively). These findings emphasise the multifactorial nature of prescribing errors, as previously established. ${ }^{46}$

This study has a number of limitations. First, it includes only one NHS board. Thus, findings are not necessarily generalisable. However, the methodology is transferable, given the ubiquity of incident reporting systems. Second, analysis of the presence and contribution of errorproducing factors depended on both the level of detail in the reporter's description of the incident (which varied), and subjective evaluation by the researcher, risking interpersonal variation and bias. Third, evidence suggests that incident-reporting systems significantly under-report the frequency of prescribing errors. ${ }^{7}$ Furthermore, bias may exist in the type and severity of patient safety incidents reported. ${ }^{8}$ Thus, the analysed incidents are unlikely to represent the rates or characteristics of all prescribing errors locally.

Given these limitations, the study findings are likely most effectively utilised in providing an impetus and evidence base for targeting local quality improvement interventions towards addressing the commonly implicated drugs, error types and error-producing factors identified. This could involve continuous quality improvement, consisting of 'plan-do-studyact' cycles of iterative change, at a departmental/ ward level, as successfully trialled elsewhere. ${ }^{9}$ Of note, electronic prescribing has been introduced more broadly across the NHS board since the data collection period. Evidence suggests that this may also reduce the frequency of medication errors, however local evaluation is required. ${ }^{10}$

Our initial intervention is the delivery of teaching sessions to final year medical undergraduates prior to commencing Foundation Training, which generate learning from anonymised prescribing-related adverse incidents, involving the commonly implicated drugs and recurrent error types identified. These sessions intend to promote safe prescribing by making learning increasingly relevant (as reflected in learner feedback); raising awareness of contextual factors contributing to errors; and fostering a safety culture and familiarity with incident reporting systems from early in training. However, the evidence linking teaching in isolation with reduction in error rates is lacking. ${ }^{11}$ Therefore, it is imperative that moving forward this educational approach proceeds in 
Table 1 Most commonly reported prescribing error types

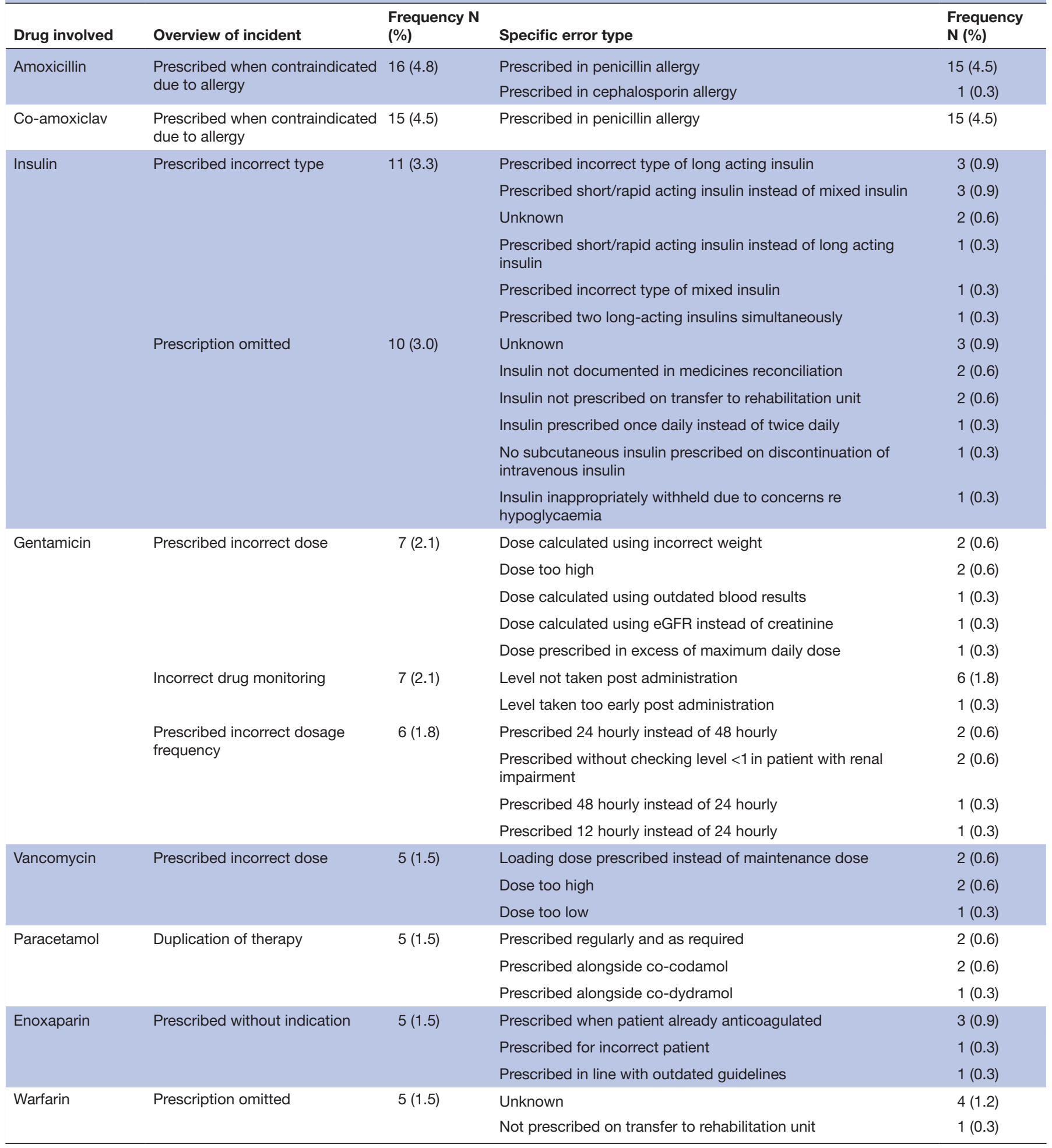

tandem with targeted, on the ground quality improvement initiatives, to optimise efforts to promote safe prescribing.

Twitter Natalie Lane @nataliemlane

Contributors NL was responsible for the study design, data collection, data analysis, initial drafting of the manuscript and subsequent redrafting and revision of the final manuscript. IH developed the concept of the study, provided supervision and reviewed the initial drafts and final manuscript.

Funding The authors have not declared a specific grant for this research from any funding agency in the public, commercial or not-for-profit sectors.

Competing interests None declared.

Patient and public involvement Patients and/or the public were not involved in the design, or conduct, or reporting or dissemination plans of this research. 
Patient consent for publication Not required.

Provenance and peer review Not commissioned; externally peer reviewed.

Data availability statement № data are available.

Open access This is an open access article distributed in accordance with the Creative Commons Attribution Non Commercial (CC BY-NC 4.0) license, which permits others to distribute, remix, adapt, build upon this work non-commercially, and license their derivative works on different terms, provided the original work is properly cited, appropriate credit is given, any changes made indicated, and the use is non-commercial. See: http://creativecommons.org/licenses/by-nc/4.0/.

ORCID iD

Natalie Lane http://orcid.org/0000-0003-3586-6536

\section{REFERENCES}

1 Donaldson LJ, Kelley ET, Dhingra-Kumar N, et al. Medication without harm: who's third global patient safety challenge. The Lancet 2017;389:1680-1.

2 Royal College of Physicians. Supporting junior doctors in safe prescribing, 2017.

3 World Alliance for Patient Safety. Who draft guidelines for adverse event reporting and learning systems: from information to action, 2005.
4 Tully MP, Ashcroft DM, Dornan T, et al. The causes of and factors associated with prescribing errors in hospital inpatients: a systematic review. Drug Saf 2009;32:819-36.

5 Reason J. Human error. Cambridge University Press, 1990.

6 Ross S, Ryan C, Duncan EM, et al. Perceived causes of prescribing errors by junior doctors in hospital inpatients: a study from the protect programme. BMJ Qual Saf 2013;22:97-102.

7 Westbrook JI, Li L, Lehnbom EC, et al. What are incident reports telling us? A comparative study at two Australian hospitals of medication errors identified at audit, detected by staff and reported to an incident system. Int J Qual Health Care 2015;27:1-9.

8 Sari AB-A, Sheldon TA, Cracknell A, et al. Sensitivity of routine system for reporting patient safety incidents in an NHS Hospital: retrospective patient case note review. BMJ 2007;334:79.

9 Bain A, Silcock J, Kavanagh S, et al. Improving the quality of insulin prescribing for people with diabetes being discharged from hospital. BMJ Open Qual 2019;8:e000655.

10 Roumeliotis N, Sniderman J, Adams-Webber T, et al. Effect of electronic prescribing strategies on medication error and harm in hospital: a systematic review and meta-analysis. J Gen Intern Med 2019;34:2210-23.

11 Bos JM, van den Bemt PMLA, de Smet PAGM, et al. The effect of prescriber education on medication-related patient harm in the hospital: a systematic review. Br J Clin Pharmacol 2017;83:953-61. 